\title{
Dance Functional Outcome Survey: Development and Preliminary Analyses
}

\section{(ㄷ) (i) (으 $\Theta$}

\author{
Authors \\ Shaw Bronner, Igor Reis Urbano
}

\author{
Affiliation \\ ADAM Center, New York, NY United States \\ Key words \\ ballet, Likert scale, modern dance, orthopedic injury, \\ questionnaire, self-report, visual analog scale \\ $\begin{array}{ll}\text { received } & 20.12 .2017 \\ \text { revised } & 22.07 .2018 \\ \text { accepted } & 26.08 .2018\end{array}$

\section{Bibliography} \\ DOI https://doi.org/10.1055/a-0729-3000 \\ Sports Medicine International Open 2018; 2: E191-E199 \\ (c) Georg Thieme Verlag KG Stuttgart · New York \\ ISSN 2367-1890

\section{Correspondence} \\ Dr. Shaw Bronner, PhD, PT, OCS \\ ADAM Center, \\ 322 West 52nd Street \#199 \\ New York, NY 10101 \\ United States \\ Tel.: + 1/347/688 9351, Fax: + 1/718/8417116 \\ shaw.bronner@gmail.com
}

\begin{abstract}
The Dance Functional Outcome Survey (DFOS) was developed as a self-report questionnaire for healthy and injured ballet and modern dancers, focusing on the low back and lower extremities. Our aim was to determine factor analysis and internal consistency of the 16 items and to investigate test-retest and equivalence reliability and validity of the DFOS compared to three orthopedic outcomes instruments. Data were collected from 80 healthy and injured adult ballet and modern pre-professional and professional dancers. DFOS Likert-type and visual analog scales were completed twice within 4-9 days to study test-retest reliability. The Cincinnati Knee Rating System, Olerud and Molander Foot-Ankle Questionnaire, and Oswestry Disability Index were used to assess concurrent validity using intraclass correlation coefficients in SPSS, $p<0.05$. To determine instrument dimensions and internal consistency of the items, we conducted exploratory factor analysis and calculated Cronbach's $\alpha$ in JASP. DFOS demonstrated single factor loading and high Cronbach's $\alpha$; high test-retest repeatability and equivalence reliability ( $r=0.74-0.99)$ and acceptable criterion validity compared to the orthopedic outcomes instruments $(r \geq 0.67)$. These results support further study of a revised 14 item Likert-version DFOS for repeatability, validity and responsiveness.
\end{abstract}

\section{Introduction}

Surveillance of dance injuries is necessary to determine incidence, assess effectiveness of intervention, and measure functional recovery [9]. A critical component is dance-relevant outcome measurement, reflecting health status and change over time.

There are a number of outcome questionnaires with sport-related content $[2,4,7,30,31]$; yet the absence of instruments specific to dance was a problem. We reviewed generic, joint and sport outcome tools and found ceiling effects and problems with validity for dance. The Dance Functional Outcome Survey (DFOS) was developed to fill this gap [12].

Two outcome questionnaire formats are Likert-type scales (LS) and visual analog scales (VAS) [24]. LS are most common, requiring answers of agreement or disagreement to a statement [37]. There is no consensus about the optimal number of responses in LS, with 3-7 responses commonly used [45]. VAS assesses a dimension

through a point made along a $10 \mathrm{~cm}$ line representing from the best to worst possible state $[24,32,37]$. LS and VAS demonstrate reliability, validity and responsiveness [5, 14, 19, 24, 27, 32, 43, 45].

The aim of the present study was to investigate face validity, factor structure and internal consistency; test-retest and equivalence reliability; and concurrent validity of the DFOS compared to established orthopedic instruments. Because the majority of dance injuries are to the low back and lower extremities $[6,10,21,25,40]$, we selected three region-specific tools to use as construct measures.

\section{Methods}

\section{Subjects}

Sample size was based on a priori analysis for test-retest reliability with one group, two measurements, effect size $\delta=0.25$, power $=0.95$, 
$\alpha=0.05$ [18] resulting in 54 subjects. As DFOS contained 16 items, based on a ratio of 5 subjects per item [1], we estimated 80 participants to perform exploratory factor analysis (EFA).

Healthy dancers were recruited from companies and pre-professional schools, and newly injured dancers were referred from dance medicine physical therapy clinics. Inclusion criteria were: i) more than 3 yrs of training including ballet and/or modern dance; ii) intermediate to expert skill level; and iii) $\geq 18$ yrs. Exclusion criteria were non-English speaking or pregnancy. All subjects gave written informed consent in compliance with University Internal Review Board guidelines [23].

\section{Instruments}

Following review of outcome tools, we interviewed dance medicine clinicians and dancers about functional limitations, available outcome measures, and their ability to measure change and recovery. Consequently, we developed a preliminary 20-question DFOS. Our conceptual framework included: i) content model of physical skills related to activities of daily living (ADL) and dance [29]; ii) applicability to low back and lower extremity orthopedic conditions; iii) ability to document function in healthy and injured states; iv) demonstrated reliable and valid measurement; and v) efficiency of administration, scoring, and recording.

Questions were generated in LS and VAS formats. LS were comprised of 6 answers scored from $0-5$-points. A final self-rating numeric score (0-100) assessed current functional state [11]. VAS were anchored with 2-descriptors: No limitation and Severely limited.

To assess face validity, DFOS was submitted to an expert panel of 17 dance professionals (clinicians and dancers) and a specialist in outcomes development. They assessed what body regions were best reflected, if it was user-friendly, applicable to a wide range of training levels and populations, and how dancers would respond to the test length. We revised or dropped questions if $20 \%$ or more of the experts questioned them. The remaining 16 questions were reweighted and assigned either $0-5$ or $0-10$ points based on expert item ranking. A score of 100 represented maximal function, with $A D L$ and Technique representing 40 and 60 points, respectively.

For validity analyses, the DFOS was compared to three self-report outcome questionnaires: i) Cincinnati Knee Rating System (CinnKnee) [2]; ii) Olerud and Molander Foot-Ankle Questionnaire (FAQ) [36]; and iii) Oswestry Disability Index (Oswestry) [17]. All were well-studied for psychometric properties, internal consistency, test-retest reliability, and responsiveness [17, 31, 35, 44].

CinnKnee assesses symptoms and limitations related to anterior cruciate ligament deficiency and reconstruction [2,31] with 8 questions related to $A D L$ and sports. A self-rating question is graded from 0-100 points. FAQ evaluates outcomes with respect to foot-ankle dysfunctions $[30,36]$ with 9 questions related to ADL and sports [30, 36]. Oswestry assesses spinal disorders [17] with 10 questions focused on ADL activities in LS format.

Upon enrollment, subjects completed a consent form, DFOS-LS ( $\triangleright$ Table 1) and DFOS-VAS ( $\triangleright$ Table 2 ) in randomized order, with CinnKnee, FAQ, and Oswestry separating them. Within 4-9 days, dancers returned to complete LS and VAS a second time in randomized order, with a demographic questionnaire between them.

\section{Data analysis}

All data were entered into Excel. DFOS, CinnKnee, FAQ and Oswestry data were transformed to sub and total scores. Higher scores reflected higher function. Individualized survey items, organized into categories based on similar concepts, were categorized as i) ADL; ii) pain; iii) dance technique or sports activities; iv) total; and v) self-rating scores.

Exploratory factor analysis (EFA) was conducted to identify latent constructs and underlying facture structure using parallel analysis, Eigen values, scree plots, suppression of small coefficients, and rotation. Cronbach's $\alpha$ was calculated to estimate internal consistency of the items, with Cronbach's $\alpha>0.70$ considered acceptable and $>0.90$ excellent [26]. Data analyses were conducted using JASP open-source software (JASP, Version 0.8.1.2, University of Amsterdam, The Netherlands).

Intraclass correlation coefficients (ICC 2,1 ) (SPSS v.23, IBM Corp, Armonk, NY) determined: i) test-retest reliability (LS v. LS, VAS v. VAS); ii) equivalence reliability (LS v. VAS); and iii) concurrent validity (DFOS v. CinnKnee, FAQ and Oswestry), $\mathrm{p}<0.05$. We compared DFOS scores of Healthy v. Injured groups using 2-tailed t-tests for independent samples with equal variances not assumed, $p<0.05$. For validity analyses, we compared total scores, sub-scores, individual questions and self-rating. Interpretation of correlation strength were based on accepted guidelines (low $\leq 0.49$, moderate $0.50-0.69$, high $0.70-1.00$ ) [34].

To determine whether there was systemic bias in location of scoring, known as end-aversion bias, we compared the percentage of scorings in each LS category with VAS percentages. Answers were recorded into five even bin categories to assess bias.

\section{Results}

\section{Subjects}

Eighty dancers participated (47 females, 33 males, 49 healthy, 31 injured) ( $\triangleright$ Table 3 ). Mean age was $26 \pm 5$ yrs with $15 \pm 6$ yrs dance training. Sixty-six participants had $5 \pm 5$ yrs professional experience. Body region frequencies represented in the injured population included $29 \%$ foot, $10 \%$ ankle, $16 \%$ leg, $26 \%$ knee, $6 \%$ thigh, $6 \%$ hip, and $6 \%$ low back.

\section{Exploratory factor analysis and internal consistency}

Parallel analysis resulted in 2-factor loading with several items loading onto more than 1 factor. Internal consistency of the 16 items was Cronbach's $\alpha=0.90$. We re-ran EFA parallel analysis after eliminating the 2 lowest loadings (Q11. bending of the trunk and Q12. arabesque). This resulted in 1-factor loading with inter-item correlations ranging from $0.74-0.95$. We also ran EFA with Eigenvalue $>1$, suppression of coefficients $<0.40$, and oblique oblimin rotation to determine best fit [46]. This resulted in similar results with an Eigenvalue $=11.349$ accounting for $81.6 \%$ of the variance and Kaiser-Meyer-Olkin $=0.937$. After elimination of the 2 items, Cronbach's $\alpha=0.97$ was improved.

\section{Reliability}

Test-retest reliability for DFOS LS v. LS and VAS v. VAS were high, (total, ADL, Technique $r>0.90$ ) ( $\triangleright$ Table 4). Examination of the two 
> Table 1 Dance Functional Outcome Survey (DFOS) 16-item Likert Version.

Please answer every section, and mark in each section the one statement which most applies to you. We realize that two statements in any one section may relate to you, but just mark the one that most closely describes your level now. These questions are based only on what you can do at this time. Do not compare yourself to other dancers. If a section is not applicable, please skip it.

\section{A. GENERAL PERFORMANCE}

\section{Overall Activity Level}

- I have no limitations. I am able to do everything, including strenuous dancing and exercise.

- I can dance, but at a lower level. I must guard myself and limit the amount of heavy dancing.

- Light dancing is possible with occasional problems. I must avoid certain movements.

- No dancing is possible. Daily activities are possible with occasional problems.

- Daily activities cause moderate problems.

- Daily activities cause severe problems.

\section{Movement Quality}

- I feel confident that I can perform at the same level and quality as prior to my injury. I am able to articulate my limbs with $100 \%$ certainty or clarity.

- I feel confident that I am almost at the same level and quality of performance as prior to my injury. I am able to articulate my limbs with $80 \%$ certainty or clarity.

- I am improving but have a ways to go before I am back to the level and quality I was prior to my injury. I am able to articulate my limbs with $60 \%$ certainty or clarity.

- I am improving but can only control my movement quality some of the time. I am able to articulate my limbs with $40 \%$ certainty or clarity.

- I am improving but only beginning to focus on movement quality. I am able to articulate my limbs with $20 \%$ certainty or clarity.

- I am improving but am working on basics and not able to focus on quality at this time.

\section{Walking}

- Normal and unlimited, including hills.

- Slight problems, relatively unlimited distances.

- Mild problems, most surfaces, up to half a mile or 10 blocks.

- Moderate problems, flat surfaces, no more than 1/4 mile or 5 blocks.

- Severe problems, only $1 / 8$ mile or 2-3 blocks.

- Severe problems, need cane or crutches.

\section{Stairs}

- Normal, unlimited up and down stairs.

- Slight problems, need to be careful, particularly (circle one) up / down stairs.

- Mild problems, have to go slowly, particularly (circle one) up / down stairs.

- Moderate problems, only 10-15 steps possible, particularly (circle one) up / down stairs.

- Severe problems, require a banister for support, particularly (circle one) up / down stairs.

- Severe problems, only 0-5 steps with support, especially (circle one) up / down stairs.

\section{Stability and Symptoms}

- I can do everything without symptoms of: giving out, locking, catching, grinding, or feeling weak.

- I only have symptoms (of giving out, locking, catching, grinding, or feeling weak) with strenuous dancing or exercise.

- I only have symptoms (of giving out, locking, catching, grinding, or feeling weak) with moderate dancing; it limits my vigorous activities.

- Because I have symptoms (of giving out, locking, catching, grinding, or feeling weak) with light dancing, it limits almost all of my dancing. I occasionally have symptoms with walking or light household work.

- I have symptoms frequently with simple activities such as walking. I must guard my injury at all times.

- I have severe problems with symptoms (of giving out, locking, catching, grinding, or feeling weak). I can't do much of anything without having symptoms.

\section{Pain}

- I have no pain.

- I have occasional pain with strenuous dance or exercise. I don't think that things are entirely back to normal. Limitations are mild and tolerable if I am careful.

- There is occasional pain with moderate dancing or light exercise.

- I have pain with any dancing, exercise, or light recreational activities. Occasional pain is brought on by daily activities.

- Pain is a significant problem with activities such as simple as walking. The pain is relieved by rest. I can't participate in dancing or exercise.

- I have pain at all times, even during walking, standing, or light household work.

\section{B. TECHNIQUE SPECIFIC}

\section{Plié}

- Able to fully perform grand plié in all positions, including fourth and fifth.

- Able to perform grand plié in first and second only.

- Able to perform grand plié in second position only.

- Cannot grand plie', but can demi-plié in all positions.

- Have some difficulty with demi-plié.

- Cannot demi-plié.

\section{Développé}

- I am able to fully perform all parts of développé to the front or side without a problem.

- I have slight problems performing développé to the front or side.

- I have mild problems fully extending my leg in développé to the front or side, and must dèveloppé at a lower height.

- I have moderate problems fully extending my leg in développé to the front or side and must mark it, but I can fully passé.

- I do not développé to the front or side at all, but can do a full passé.

- I cannot perform a full passé. 
- Table 1 Continued.

\section{Relevé Balance}

(If you do pointe work, indicate whether you can perform the indicated level on pointe.)- Able to attain and maintain my balance in relevé / pointe on the involved side without a problem.

- Able to attain and maintain my balance in relevé / pointe on the involved side with only slight problems.

- Able to attain and maintain my balance in relevé / pointe on the involved side with moderate difficulty.

- Able to relevé but can't maintain the balance on the involved side without barre assistance.

- Able to maintain my balance on flat foot, but cannot balance in relevé.

- Cannot relevé or maintain my balance on the involved side on flat foot.

\section{Bending of the Trunk}

- Able to fully perform: grand port de bras ronversé and all other cambré port de bras (full rotational movements of the trunk - i. e., fully forward, side, and back).

- Able to perform, but not quite fully: grand port de bras ronversé (rotational movements of the trunk - i. e., forward, side, and back).

- Able to perform with slight problems: cambré port de bras forward, back, and side (trunk forward, backward, and sidebending without rotational component).

- I have moderate problems with: cambré port de bras forward, back, and side (trunk forward, backward, and sidebending).

- At best, I can only mark cambré port de bras forward and back (trunk forward and backward bending).

- I cannot perform cambré port de bras forward and back (trunk forward and backward bending).

\section{Arabesque}

- Able to fully perform: arabesque (to my usual height), and grand battement derrière (to the back).

- Able to perform, but not quite fully: arabesque, and grand battement derrière (to the back).

- Able to perform with slight problems: arabesque, and grand battement derrière (to the back).

- I have moderate problems with: arabesque, and grand battement derrière (to the back).

- At best, I can only mark arabesque, and grand battement derriére (to the back).

- I cannot perform arabesque, or grand battement derrière (to the back).

\section{Rond de jambe}

- Able to fully perform as much and as often as required, at $90^{\circ}$ : grand rond de jambe en l'aire a la seconde (rotational movements of the leg in the air).

- Able to perform at reduced speed: rond de jambe en l'aire a la seconde (rotational movements of the leg in the air) .

- Able to perform with mild problems such as reduced number and speed: rond de jambe en l'aire a la seconde (rotational movements of the leg in the air).

- Able to perform with moderate problems such as reduced number, speed, and height (at $45^{\circ}$ ): rond de jambe en l'aire a la seconde (rotational movements of the leg in the air).

- I mark or avoid all rond de jambe en l'aire type movements (rotational movements of the leg in the air).

- I am unable to perform rond de jambe en l'aire a la seconde (rotational movements of the leg in the air) at all.

13. Kneeling / Floorwork

- Able to fully perform floorwork or kneeling activities, without limitations .

- Able to perform floorwork or kneeling activities, with mild limitations.

- Able to perform floorwork or kneeling activities, with moderate limitations.

- Able to perform floorwork or kneeling activities, with more moderate limitations: may require less repetitions or slight modification

- Severe problems, require support or modification.

- Severe problems, unable to do.

\section{Turning}

- Able to fully perform unlimited multiple turns of all kinds, on either leg (to the extent you were able prior to your injury).

- Able to perform, but not quite fully, turns of all kinds, on either leg (to the extent you were able prior to your injury).

- Able to perform with slight problems, turns of most kinds, on either leg. I have to be careful about placement.

- I have moderate problems with turning. I am able to do single inside and outside turns on the involved side.

- Severe problems, no turning. I only do turn preparation and balance in relevé on the involved side.

- Severe problems, unable to balance on the involved side.

\section{Jumping}

- Able to fully perform everything: all grand and petit allegro (big and small jumping) combinations, including beats (to the extent you were able prior to your injury). Take off power is normal and unlimited. Able maintain my balance when landing from a jump or hop.

- Able to perform, but not quite fully, grand and petit allegro (big and small jumping) combinations (to the extent you were able prior to your injury). Take-off power and ability to maintain my balance when landing are pretty good.

- Able to perform with slight problems and some guarding: grand and petit allegro, and balance when landing from jumps or hops. I avoid most difficult jumps. Unable to do repeated jumps.

- I have moderate problems with jumping. I am only doing simple jumps in the center.

- Severe problems, affects all jumping in center floor. Can do simple jumps at the barre.

- Severe problems, no jumping activity possible.

\section{Across the Floor / Traveling / Running}

- Able to fully perform all traveling combinations (change of direction, pivots, quick stops and starts, or run) at full speed.

- Able to perform, but not quite fully, all traveling combinations (change of direction, pivots, quick stops and starts, or run).

- Able to perform, with slight problems, traveling combinations (change of direction, pivots, quick stops and starts, or run) at reduced speed.

- I have moderate problems, and must move slowly and carefully in traveling combinations (change of direction, pivots, quick stops and starts, or run).

- I have severe problems, and must avoid most traveling combinations. I stick to barre and adagio (or center floor).

- I avoid all traveling combinations.

Compared to before my injury, if I had to give my dancing performance a grade from 0 to 100 , with 0 being the worst and 100 being the best, I would give myself a 
- Table 2 Dance Functional Outcome Survey (DFOS) 16-item Analog Version.

\begin{tabular}{|c|c|}
\hline \multicolumn{2}{|c|}{$\begin{array}{l}\text { Please draw a vertical slash to indicate your level for the following } \\
\text { activities: }\end{array}$} \\
\hline \multicolumn{2}{|c|}{ C. GENERAL PERFORMANCE } \\
\hline \multicolumn{2}{|l|}{ 1. Overall Activity } \\
\hline \multicolumn{2}{|c|}{$\begin{array}{l}\text { Are there any limitations that interfere with your overall activity level } \\
\text { (strenuous dance and exercise)? }\end{array}$} \\
\hline \multicolumn{2}{|l|}{ No limitations } \\
\hline \multicolumn{2}{|l|}{ 2. Movement Quality } \\
\hline \multicolumn{2}{|c|}{ How affected is your movement quality and level of performance? } \\
\hline No limitations & Severely limited \\
\hline \multicolumn{2}{|l|}{ 3. Walking } \\
\hline \multicolumn{2}{|c|}{ How affected is your walking? (Consider varying distances and surfaces). } \\
\hline No limitations & Severely limited \\
\hline \multicolumn{2}{|l|}{ 4. Stairs } \\
\hline \multicolumn{2}{|c|}{ How affected is your ability to climb stairs? } \\
\hline No limitations & Severely limited \\
\hline
\end{tabular}

Do symptoms of giving out, locking, catching, grinding, or feeling weak interfere with your activities?
No limitations
Severely limited

\section{Pain}

Does pain interfere with your activities?

\begin{tabular}{|l|}
\multicolumn{1}{|c|}{ No limitations } \\
\hline B. TECHNIQUE SPECIFIC \\
\hline 7. Plié
\end{tabular}

How affected is your ability to perform demi- and grand-plié in all positions?

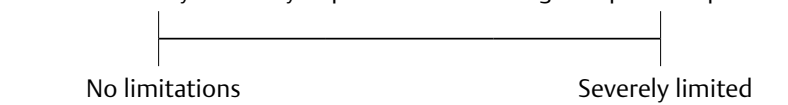

8. Développé
and side)?

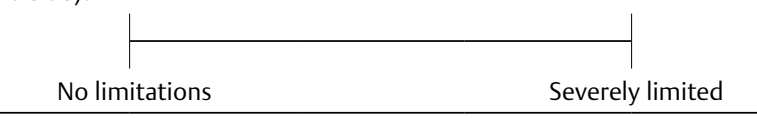

\section{Relevé Balance}

How affected is your ability to attain and maintain balance in relevé / pointe (if applicable) on the involved side?

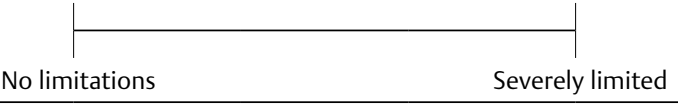

\section{Bending of the Trunk}

How affected is your ability to perform grand port de bras ronversé (full rotational movements of the trunk - i.e., fully forward, side, and back)?

\begin{tabular}{c|c|} 
& \\
No limitations & Severely limited \\
\hline
\end{tabular}

- Table 2 Continued.

\begin{tabular}{|l|}
\hline 11. Arabesque \\
\hline $\begin{array}{l}\text { How affected is your ability to perform arabesque and grand battement } \\
\text { derriére (to the back)? } \\
\text { No limitations }\end{array}$ \\
\hline 12. Rond de jambe
\end{tabular}

How affected is your ability to perform grand rond de jambe en l'aire, a la seconde, and a terre (rotational movements of the leg in the air and on the floor)?

\begin{tabular}{|c|} 
No limitations \\
\hline 13. Kneeling / Floorwork
\end{tabular}

How affected is your ability to perform floorwork or kneeling activities?

\section{Turning}

How affected is your ability to perform unlimited, multiple turns of all kinds (to the extent you were able prior to your injury), on either leg?

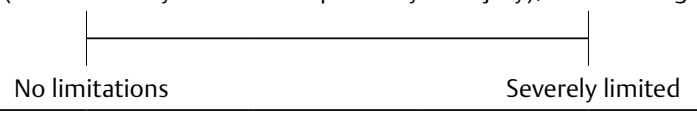

\section{Jumping}

How affected is your ability to fully perform all grand and petit allegro (big and small jumping) combinations, including beats (to the extent you were able prior to your injury)? (Consider take-off power and control of landing as well).

No limitations

Severely limited

\section{Across the Floor / Traveling / Running}

How affected is your ability to fully perform all traveling combinations (change of direction, pivots, quick stops and starts, or run) at full speed?

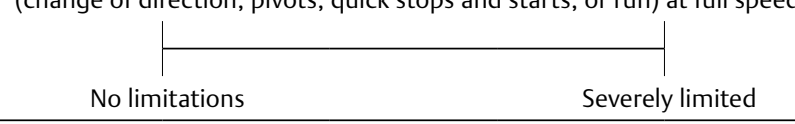

Compared to before my injury, I would rate my dancing performance:

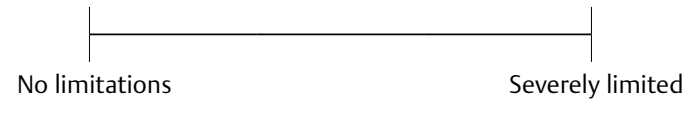

back items revealed moderate (VAS $r=0.53)$ to high $(L S r=0.88)$ coefficients. When those questions were eliminated, test-retest correlations improved both LS and VAS. Reliability coefficients for self-rating scores were high $(L S r=0.99$, VAS $r=0.86)$. Significant differences were found between Healthy and Injured groups for all DFOS scores $(p<0.001)$.

Equivalent reliability coefficients comparing LS v. VAS for total, Technique and self-rating scores were high $(r>0.70)$ ( $\vee$ Table 4$)$, but $A D L$ and back questions were only moderate. Removal of the two back-related items improved Technique and total score correlations. Analysis of systemic bias found a $4 \%$ higher bias toward end-bin answers in LS. 
- Table 3 Demographics.

\begin{tabular}{|c|c|c|c|}
\hline Gender & Male & Female & Total \\
\hline Subjects (\%) & $33(41 \%)$ & 47 (59\%) & $80(100 \%)$ \\
\hline Healthy (\%) & $20(25 \%)$ & $29(36 \%)$ & $49(61 \%)$ \\
\hline Injured (\%) & $13(16 \%)$ & $18(23 \%)$ & $31(39 \%)$ \\
\hline Age (yrs) & $26.52 \pm 4.75$ & $24.66 \pm 5.66$ & $25.69 \pm 5.49$ \\
\hline Dance training (yrs) & $11.87 \pm 4.74$ & $15.79 \pm 6.57$ & $14.71 \pm 6.22$ \\
\hline \# Professional (\%) & $32(97 \%)$ & $33(70 \%)$ & $65(81 \%)$ \\
\hline $\begin{array}{l}\text { Professional } \\
\text { experience (yrs) }\end{array}$ & $5.26 \pm 3.99$ & $3.74 \pm 4.71$ & $4.79 \pm 4.85$ \\
\hline \multicolumn{4}{|l|}{ Primary technique } \\
\hline Modern (\%) & $21(26 \%)$ & $19(24 \%)$ & $40(50 \%)$ \\
\hline Ballet (\%) & $1(1 \%)$ & $4(5 \%)$ & $5(6 \%)$ \\
\hline Ballet /Modern (\%) & $11(14 \%)$ & $24(30 \%)$ & $35(44 \%)$ \\
\hline \multicolumn{4}{|l|}{ Ethnicity } \\
\hline Caucasion (\%) & $11(14 \%)$ & $23(29 \%)$ & $34(43 \%)$ \\
\hline African American (\%) & $21(26 \%)$ & $15(19 \%)$ & $36(45 \%)$ \\
\hline Other (\%) & $2(3 \%)$ & $9(11 \%)$ & $10(13 \%)$ \\
\hline
\end{tabular}

- Table 4 Test-retest reliability of 16-item DFOS.

\begin{tabular}{|l|c|c|c|}
\hline Scores & $\begin{array}{c}\text { Likert v. } \\
\text { Likert }\end{array}$ & $\begin{array}{c}\text { Analog v. } \\
\text { Analog }\end{array}$ & $\begin{array}{c}\text { Likert v. } \\
\text { Analog }\end{array}$ \\
\hline Total & 0.99 & 0.94 & 0.74 \\
\hline ADL & 0.99 & 0.94 & 0.60 \\
\hline Technique & 0.99 & 0.91 & 0.77 \\
\hline Back questions & 0.88 & 0.53 & 0.51 \\
\hline Total (no back) & 0.99 & 0.96 & 0.76 \\
\hline Technique (no back) & 0.99 & 0.93 & 0.83 \\
\hline Self-rating & 0.99 & 0.86 & 0.79 \\
\hline Abbreviations: versus = v; activities of daily living = ADL \\
\hline
\end{tabular}

- Table 5 Validity of 16-item DFOS and other instruments.

\begin{tabular}{|c|c|c|c|}
\hline Scores & $\begin{array}{l}\text { DFOS v. } \\
\text { CinnKnee }\end{array}$ & $\begin{array}{l}\text { DFOS v. } \\
\text { FAQ }\end{array}$ & $\begin{array}{l}\text { DFOS v. } \\
\text { Oswestry }\end{array}$ \\
\hline Total score & 0.75 & $0.67^{*}$ & 0.73 \\
\hline ADL & 0.68 & 0.42 & 0.67 \\
\hline Walking & 0.77 & & \\
\hline $\begin{array}{l}\text { Overall mvt v. Overall } \\
\text { activity, Work }\end{array}$ & 0.77 & 0.78 & \\
\hline Stairs & 0.91 & 0.28 & \\
\hline Stability & 0.21 & 0.37 & \\
\hline Pain & 0.37 & 0.48 & 0.48 \\
\hline Technique/Sport & $0.66 \dagger$ & 0.45 & 0.67 \\
\hline Plié v. Squat & & 0.82 & \\
\hline $\begin{array}{l}\text { Turn, Jump, Travel v. } \\
\text { Run, Jump, Twist }\end{array}$ & 0.65 & 0.70 & \\
\hline Self-rating & 0.60 & & 0.43 \\
\hline \multicolumn{4}{|c|}{$\begin{array}{l}\text { * FAQ total score minus stiffness question; } \dagger \text { Technique score minus } 2 \\
\text { back items; Abbreviations: Cincinnati Knee Rating System = CinnKnee; } \\
\text { Foot-Ankle Questionnaire = FAQ; versus=v; activities of daily } \\
\text { living = ADL; movement = mvt }\end{array}$} \\
\hline
\end{tabular}

\section{Validity}

We report LS comparisons because test-retest LS correlations were slightly higher than VAS compared to the orthopedic outcomes instruments. Total scores in DFOS-LS v. CinnKnee demonstrated high validity $(r=0.75)$ ( $\triangleright$ Table 5$)$. ADL sub-scores were moderate $(r=0.68)$. High correlations were found in items related to walking, overall movement, and stairs ( $r=0.77-0.91)$, but low correlations for pain $(r=0.37)$ and stability $(r=0.21)$. DFOS Technique $v$. CinnKnee Sports subsets were moderate $(r=0.56)$, with improvement when back items were eliminated $(r=0.66)$. Turning, traveling, jumping-twisting questions were moderately correlated $(r=0.65)$, as well as self-rating for DFOS v. CinnKnee $(r=0.60)$.

DFOS v. FAQ total scores were moderate $(r=0.67)$, whereas ADL sub-scores were low $(r=0.42)$. DFOS overall movement v. FAQ overall activity level/work had a high correlation $(r=0.78)$. Pain $(r=0.48)$ and stairs $(r=0.28)$ presented low values, as well as DFOS Technique v. FAQ Sport $(r=0.29)$. When DFOS back items were eliminated, correlation between Technique v. Sport subsets improved $(r=0.45)$. There was high correlation for DFOS plié v. FAQ squatting $(r=0.82)$ and DFOS jumping, traveling v. FAQ running, jumping, twisting $(r=0.70)$.

Correlations of total DFOS and Oswestry scores were high $(r=0.73)$. ADL and Technique sub-scores v. Oswestry scores were moderate $(r=0.67)$.

\section{Discussion}

We report on DFOS item generation, demonstration of face validity through expert feedback, item reduction, factor analysis and internal reliability, and further item reduction. We found high testretest and equivalence reliability and acceptable criterion validity compared to orthopedic outcomes instruments. Findings are examined in detail below.

\section{EFA and internal consistency}

Our conceptual framework involved 2 factors: ADL and Technique. EFA revealed only 1 factor. Item fit improved when 2 items were eliminated resulting in a more parsimonious variable set. Internal consistency is based on correlations between different items within the same test. High internal reliability indicated strong item covariance suggesting that the 16 items measure the same latent construct [41]. Following deletion of 2 items, Cronbach's $\alpha$ improved, substantiating EFA findings.

\section{Reliability}

Test-retest reliability of DFOS LS and VAS were high for total, ADL and Technique scores. Two items were unsatisfactory in VAS testretest and LS v. VAS comparisons. Item elimination improved internal consistency and test-retest correlations.

Differences between Healthy and Injured groups' scores suggest that DFOS differentiates functional state. The breakdown of frequencies of injuries by body region was similar to those reported in professional and pre-professional modern dance and ballet $[8,13,16,21,39,40]$. Future study of responsiveness will determine whether DFOS sensitivity reflects change with functional recovery following injury. 
End-aversion bias refers to the tendency of respondents to avoid ends of scales with extreme answers, resulting in a central tendency bias. Researchers reported greater end-aversion bias in LS $[24,43]$; others reported them in VAS [45]. We found mild systemic bias toward LS end-bin answers compared to VAS. This may be explained by LS supporting statements that subjects reported were easier to understand. Most researchers report that LS and VAS are comparable in reliability and validity, yielding similar results with no consensus about which formats have better applicability $[24,43]$. Post data collection, dancers preferred LS as easier to understand; we found LS easier to score and interpret; therefore, we selected LS for future study.

\section{Validity}

DFOS and CinnKnee total, ADL sub-scores were highly correlated as expected, as DFOS ADL questions were based on orthopedic injury-related questionnaires. However, questions about stability and pain were poorly correlated.

Data accuracy about complex concepts, such as pain or stability, is related to how concept characteristics are explored within questions [20]. Studies report LS wording can affect respondent answers, and even with multiple categories, may not suffice to describe continuous, subjective and complex perception of individual conditions [32]. Similar to DFOS, CinnKnee assessed pain and stability at differing intensities. However, CinnKnee focused on knee pain and stability [2]. In contrast, DFOS assessed clinical signs related to dance intensity not specific to one joint. DFOS may assess more components of stability and pain than CinnKnee resulting in low correlation values.

We found moderate correlations in analysis of DFOS Technique (turning, jumping, grand allegro/across the floor/traveling/running) and CinnKnee (running, jumping-twisting). The complexity and quality of dance movement must be considered because there are requirements within dance that are not considered within CinnKnee, such as turnout (hip external rotation), dynamics, extreme motions and patterns of body alignment [33]. Our results suggest DFOS more accurately reflects dancers' functionality.

DFOS and FAQ total scores were moderately correlated, whereas DFOS and FAQ ADL sub-scores were low. Yet, examination of individual items within ADL (DFOS overall activity v. FAQ work-ADL) was high. This was anticipated because items that assess general activity level were similar in orthopedic injury-related questionnaires.

Low correlations were found in DFOS items about stairs, stability and pain v. FAQ stairs, support and pain. FAQ answers focused on general symptoms or pain divorced from functionality [36]. These may be insensitive to more complex variables within ADL.

DFOS Technique and FAQ Sports sub-scores were poorly correlated. Yet we found high correlation for DFOS turning, jumping, travelling v. FAQ running, jumping and between DFOS plié v. FAQ squatting, explained by movement correspondence. In plié, a basic dance movement, the upright torso is lowered with hip-knee flexion and ankle dorsiflexion [42]. Participants considered similar function when asked about plié v. squatting, because impairment of hip, knee or ankle motion have analogous components during such activities [3, 42].

Questionnaire differences in wording, content, and task may impact subjects' understanding about functional state $[32,45]$.
FAQ focuses on tasks without considering a dance scenario. Jointspecific questions provided limited answers (no problem, impaired, impossible). DFOS provides greater scaling sensitivity per question, applicable to a number of body regions, focusing on the task performance instead of on a specific joint. For example, impairment at the hip, knee, or ankle may impact the ability to perform a plié. The 6-answers/item allows a wider range for interpretation of ability with which a task can be performed.

Although there is no optimal number of responses on LS, a high number of possible answers become more meaningful depending on context and condition [28]. In test-retest analyses, reliability coefficients were highest with a 5- to 7-point LS [38]. This indicates that DFOS may guarantee more response stability than CinnKnee or FAQ.

Correlations between DFOS total, ADL and Technique to Oswestry scores were moderate. Oswestry was developed for a general population and uses 6 -responses/item, assessing relatively low functional activity. In contrast, dancers as athletes are concerned with sport-related issues such as back flexibility, strength, and complex technical skills (e. g., turning, twisting) [47] found in DFOS.

There were several limitations. First, our sample was small and comprised primarily of professional dancers. Further investigation is needed to assess DFOS measurement properties in a broader population with greater numbers of student, ballet, and injured dancers with a range of back and lower-extremity conditions.

Second, LS and VAS DFOS were administered on the same day. A carry-over effect could bias equivalence reliability, because an individual may remember the answers given in different DFOS formats, but the two versions are extremely different. In VAS, respondents view 'How affected is your walking?' and select a place on the line between No limitations and Severely limited. In LS, participants read the walking question and select from 6 options such as 'normal and unlimited' to 'severe problems, need cane or crutches'. Researchers studying LS and VAS questionnaires typically administer both on the same day $[19,22,24]$. Comparison of time intervals for instrument test-retest reliability has demonstrated no difference between 2 days v. 2 wks [31] or same day immediate v. 10 min delayed administration [15].

\section{Conclusion}

DFOS provides detailed information about dancers' quality and capacity to perform complex tasks. Designed to assess functional outcomes related to dance movement not present on other questionnaires, these results support further study of a revised 14 -item DFOS.

\section{Acknowledgements}

The authors thank Robert Turner who assisted in developing the DFOS questionnaire, dancers who participated as subjects, dance organizations that allowed us access to these dancers, and clinicians who assisted in collecting data or helped in preliminary analyses, including Robert Turner, Sheyi Ojofeitimi, Dana Hash-Campbell, and Thales Rezende de Souza. Study design, data collection, analyses and writing were supported by the ADAM Center, New York, NY. 


\section{Funding}

This work was supported by National Institute of Health MBRS Grant \#2SO6 GM54650. Title: Effect of musculoskeletal injury on skilled movement. This funding was not subject to open access requirements.

\section{Conflict of Interest}

The authors declare that they have no conflict of interest.

\section{References}

[1] Anthoine E, Moret L, Regnault A, Sebille V, Hardouin JB. Sample size used to validate a scale: $A$ review of publications on newly-developed patient reported outcomes measures. Health Qual Life Outcomes 2014; 12: 176

[2] Barber-Westin SD, Noyes FR, McCloskey JW. Rigorous statistical reliability, validity, and responsiveness testing of the Cincinnati knee rating system in 350 subjects with uninjured, injured, or anterior cruciate ligament-reconstructed knees. Am J Sports Med 1999; 27: 402-416

[3] Basmajian JV, Harden TP, Regenos EM. Integrated actions of the four heads of quadriceps femoris: An electromyographic study. Anat Rec 1972; 172: $15-20$

[4] Binkley JM, Stratford PW, Lott SA, Riddle DL. The Lower Extremity Functional Scale (LEFS): Scale development, measurement properties, and clinical application. North American Orthopaedic Rehabilitation Research Network. Phys Ther 1999; 79: 371-383

[5] Bolton JE, Wilkinson RC. Responsiveness of pain scales: A comparison of three pain intensity measures in chiropractic patients. J Manipulative Physiol Ther 1998; 21: 1-7

[6] Bowerman E, Whatman C, Harris N, Bradshaw E, Karin J. Are maturation, growth and lower extremity alignment associated with overuse injury in elite adolescent ballet dancers? Phys Ther Sport 2014; 15: 234-241

[7] Briggs KK, Kocher MS, Rodkey WG, Steadman JR. Reliability, validity, and responsiveness of the Lysholm knee score and Tegner activity scale for patients with meniscal injury of the knee. J Bone Joint Surg Am 2006; 88: 698-705

[8] Bronner S, Bauer NG. Risk factors for musculoskeletal injury in elite pre-professional modern dancers: A prospective cohort prognostic study. Phys Ther Sport 2018; 31: 42-51

[9] Bronner S, Ojofeitimi S, Mayers L. Comprehensive surveillance of dance injuries: A proposal for uniform reporting guidelines for professional companies. J Dance Med Sci 2006; 10: 69-80

[10] Bronner S, Ojofeitimi S, Rose D. Injuries in a modern dance company: Effect of comprehensive management on injury incidence and time loss. Am J Sports Med 2003; 31: 365-373

[11] Bronner S, Ojofeitimi S, Rose D. Repair and rehabilitation of extensor hallucis longus and brevis tendon lacerations in a professional dancer. J Orthop Sports Phys Ther 2008; 38: 362-370

[12] Bronner S, Turner R. The Dance Functional Outcome System (DFOS): A new measurement tool. J Orthop Sports Phys Ther 1999; 29: A-20 (Abstract)

[13] Bronner S, Wood L. Impact of touring, performance schedule, and definitions on 1-year injury rates in a modern dance company. J Sports Sci 2017; 35: 2093-2104

[14] Brunier G, Graydon J. A comparison of two methods of measuring fatigue in patients on chronic haemodialysis: visual analogue vs. Likert scale. Int J Nurs Stud 1996; 33: 338-348
[15] Downie WW, Leatham PA, Rhind VM, Wright V, Branco JA, Anderson JA. Studies with pain rating scales. Ann Rheum Dis 1978; 37: 378-381

[16] Ekegren CL, Quested R, Brodrick A. Injuries in pre-professional ballet dancers: Incidence, characteristics and consequences. J Sci Med Sport 2014; 17: 271-275

[17] Fairbank JC, Pynsent PB. The Oswestry Disability Index. Spine (Phila Pa 1976) 2000; 25: 2940-2952; discussion 2952

[18] Faul F, Erdfelder E, Buchner A, Lang AG. Statistical power analyses using $\mathrm{G}^{*}$ Power 3.1: Tests for correlation and regression analyses. Behav Res Methods 2009; 41: 1149-1160

[19] Flynn D, van Schaik P, van Wersch A. A comparison of multi-item likert and visual analogue scales for the assessment of transactionally defined coping function. Eur J Psychol Assessment 2004; 20: 49-58

[20] Gadotti I, Vieira E, Magee D. Importance and clarification of measurement properties in rehabilitation. Braz J Phys Ther 2006; 10: 137-146

[21] Gamboa JM, Roberts LA, Maring J, Fergus A. Injury patterns in elite preprofessional ballet dancers and the utility of screening programs to identify risk characteristics. J Orthop Sports Phys Ther 2008; 38: 126-136

[22] Guyatt GH, Townsend M, Berman LB, Keller JL. A comparison of Likert and visual analogue scales for measuring change in function. J Chronic Dis 1987; 40: 1129-1133

[23] Harriss D], Macsween A, Atkinson G. Standards for ethics in sport and exercise science research: 2018 update. Int J Sports Med 2017; 38: $1126-1131$

[24] Hasson D, Arnetz B. Validation and findings comparing VAS vs. Likert scales for psychosocial measurements. Int Electronic. J Health Educ 2005; 8: 178-192

[25] Hincapié CA, Morton EJ, Cassidy JD. Musculoskeletal injuries and pain in dancers: A systematic review. Arch Phys Med Rehabil 2008; 89: 1819-1829

[26] Kline P. The Handbook of Psychological Testing. 2nd ed. London: Routledge; 2000

[27] Kuhlmann T, Dantlgraber M, Reips UD. Investigating measurement equivalence of visual analogue scales and Likert-type scales in Internet-based personality questionnaires. Behav Res Methods 2017, doi:10.3758/s13428-016-0850-x

[28] Losby ], Wetmore A.Using Likert scales in evaluation survey work. (February 14, 2012) Available from: https://www.cdc.gov/dhdsp/pubs/ docs/cb_february_14_2012.pdf

[29] Marfeo EE, Haley SM, Jette AM, Eisen SV, Ni P, Bogusz K, Meterko M, McDonough CM, Chan L, Brandt DE, Rasch EK. Conceptual foundation for measures of physical function and behavioral health function for Social Security work disability evaluation. Arch Phys Med Rehabil 2013; 94: $1645-1652$

[30] Martin RL, Irrgang J], Lalonde KA, Conti S. Current concepts review: Foot and ankle outcome instruments. Foot Ankle Int 2006; 27: 383-390

[31] Marx RG, Jones EC, Allen AA, Altchek DW, O'Brien SJ, Rodeo SA, Williams RJ, Warren RF, Wickiewicz TL. Reliability, validity, and responsiveness of four knee outcome scales for athletic patients. J Bone Joint Surg Am 2001; 83-A: 1459-1469

[32] McCormack HM, Horne D], Sheather S. Clinical applications of visual analogue scales: A critical review. Psychol Med 1988; 18: 1007-1019

[33] Motta-Valencia K. Dance-related injury. Phys Med Rehabil Clin N Am 2006; 17: 697-723

[34] Munro BH. Statistical Methods for Health Care Research. 3rd ed. Philadelphia: JB Lippincott; 1997

[35] Nilsson GM, Eneroth M, Ekdahl CS. The Swedish version of OMAS is a reliable and valid outcome measure for patients with ankle fractures. BMC Musculoskelet Disord 2013; 14: 109 
[36] Olerud C, Molander H. A scoring scale for symptom evaluation after ankle fracture. Arch Orthop Trauma Surg 1984; 103: 190-194

[37] Polit DF, Beck CT. Nursing Research: Principles and Methods. 7th ed. Philadelphia, PA: Lippincott Williams \& Wilkins; 2004

[38] Preston CC, Colman AM. Optimal number of response categories in rating scales: Reliability, validity, discriminating power, and respondent preferences. Acta Psychol (Amst) 2000; 104: 1-15

[39] Ramkumar PN, Farber J, Arnouk J, Varner KE, McCulloch PC. Injuries in a professional ballet dance company: A 10-year retrospective study. J Dance Med Sci 2016; 20: 30-37

[40] Smith PJ, Gerrie B], Varner KE, McCulloch PC, Lintner DM, Harris JD. Incidence and prevalence of musculoskeletal injury in ballet: A systematic review. Orthop J Sports Med 2015; 3: 2325967115592621

[41] Tavakol M, Dennick R. Making sense of Cronbach's alpha. Int J Med Educ 2011; 2: 53-55
[42] Trepman E, Gellman RE, Solomon R, Murthy KR, Micheli L], De Luca C]. Electromyographic analysis of standing posture and demi-plie in ballet and modern dancers. Med Sci Sports Exerc 1994; 26: 771-782

[43] van Laerhoven H, van der Zaag-Loonen HJ, Derkx BH. A comparison of Likert scale and visual analogue scales as response options in children's questionnaires. Acta Paediatr 2004; 93: 830-835

[44] Vianin M. Psychometric properties and clinical usefulness of the Oswestry Disability Index. J Chiropr Med 2008; 7: 161-163

[45] Vickers AJ. Comparison of an ordinal and a continuous outcome measure of muscle soreness. Int J Technol Assess Health Care 1999; 15: 709-716

[46] Yong AG, Pearce S. A beginner's guide to factor analysis: focusing on exploratory factor analysis. Tutor Quant Methods Psychol 2013; 9: 79-94

[47] Zamani E, Kordi R, Nourian R, Noorian N, Memari AH, Shariati M. Low back pain functional disability in athletes; conceptualization and initial development of a questionnaire. Asian J Sports Med 2014; 5: e24281 